\title{
Monitoring of peat swamp forest using PALSAR data - A trial of double bounce correction -
}

\author{
Yoshio Awaya ${ }^{* 1}$, Tomoaki Takahashi ${ }^{* 3}$, Yoshiyuki Kiyono ${ }^{* 2}$, Hideki Saito ${ }^{* 2}$, \\ Masanobu Shimada *4, Tamotsu Sato ${ }^{* 2}$, Jumpei Toriyama ${ }^{* 2}$, Yukako Monda *2, \\ I Nengah Surati Jaya ${ }^{* 5}$, M Buce Saleh ${ }^{* 5}$, Suwido H. Limin ${ }^{* 6}$, Agung R Susanto ${ }^{* 6}$ \\ and Feteria Darma ${ }^{* 6}$
}

\begin{abstract}
When synthetic aperture radar (SAR) is used to obtain remote sensing images of forests, the images can be degraded by double reflections of the radar beam, e.g., by reflecting off water surface and then tree stems or by reflecting off a fallen tree and then by other fallen stems, which together act as a corner reflector. Here, we developed a method for correcting for this effect, called the double bounce effect. To demonstrate the method, we monitored changes in a peat swamp forest around Palangka Raya in Central Kalimantan, Indonesia using ALOS/ PALSAR data. Biomass surveys were executed in plots of grass, shrub and forest and above ground biomass (AGB) was calculated. Five Fine Beam Double Polarization PALSAR images, which were obtained between July 2007 and December 2010, were used. The backscattering coefficient (BSC) increased asymptotically to the saturation level with increasing AGB. BSC of $\mathrm{HH}$ changed linearly with BSC of $\mathrm{HV}$ in areas with different biomass and without double bounce. The linear relationship between the BSC of HH and BSC of HV showed plant succession, and the change ratio of HH BSC to HV BSC show a contribution of vertical stems on BSC, since stem biomass was the main part of AGB in L-band. However, in areas such as riverside forests and fire scars where BSC suffered from double bounce (DB areas) no such relationship was observed. Because signal of $\mathrm{HH}$ returns much stronger than that of HV by double bounce, we assumed that the double bounce changes the ratio of HH BSC and HV BSC inversely. The double bounce effect on HV BSC was corrected using a linear combination of two vectors which showed the contribution of vertical stems and the contribution of double bounce. In contrast to AGB, the original BSC was higher in DB areas than in high biomass forests. However, when we applied the above correction in DB areas, the BSC anomaly in HV disappeared. Curvilinear regression models were developed to estimate AGB using the corrected HV BSC of an image acquired in July 2007. The estimated AGB was not accurate when it exceeded 100 $\mathrm{Mg} \mathrm{ha}{ }^{-1}$ due to saturation of BSC, although it was reasonable in DB areas except in the case of an image acquired in December 2010. The method for correcting AGB should be suitable for monitoring of deforestation, regeneration and regrowth of trees in areas with low biomass in peat swamp forest.
\end{abstract}

Keywords: Central Kalimantan, biomass, double bounce, PALSAR, peat swamp forest

Corresponding author: Yoshio Awaya

*1 River Basin Research Center, Gifu University, 1-1, Yanagido, Gifu 501-1112 Japan

E-mail: awaya@green.gifu-u.ac.jp (Y. Awaya)

${ }^{2}$ Forestry and Forest Products Research Institute, 1, Matsunosato, Tsukuba, Ibaraki 305-8687 Japan

*3 Kyshu Research Center, Forestry and Forest Products Research Institute, 4-11-16, Kurokami, Chuoh-ku, Kumamoto 860-0862 Japan
${ }^{* 4}$ Earth Observation Research Center, Japan Aerospace Exploration Agency (JAXA), 2-1-1, Sengen, Tsukuba, Ibaraki 305-8505 Japan

${ }^{* 5}$ Bogor Agricultural University, J1. Lingkar Akademik Kampus IPB Darmaga, Bogor 16680 Indonesia

*6 University of Palangka Raya, Jalan Yos Sudarso, Palangka Raya, Kalimantan Tengah 73112 Indonesia 


\section{INTRODUCTION}

About $20 \%$ of anthropogenic carbon dioxide emission is caused by land use changes in the tropics dominated by tropical deforestation (IPCC 2007). Because of this situation, protection of forests in the tropics has been an important world-wide political problem. Therefore efforts and actions to reduce deforestation, maintain, and conserve forest carbon stocks in developing countries are mandatory (Reducing Emissions from Deforestation in Developing countries, REDD) (UNFCC 2007). Implementation of policies to reduce emissions from deforestation require effective deforestation monitoring systems that are reproducible, provide consistent results, meet standards for mapping accuracy, and can be implemented at the national level (DeFriEs et al. 2007).

Remotely sensed data supported by ground observations are key tools for effective monitoring of forest change. Because forests occupy huge areas in the tropics and elsewhere in the world, it is difficult to monitor them by field surveys. Therefore satellite images which cover large areas would reduce survey efforts and costs, if the images are used properly. Detecting deforestation and forest degradation is essential to understand the status of a forest and to make plans for protecting forests in the tropics for REDD or Reducing Emissions from Deforestation in Developing countries plus (REDD plus). Optical sensor images are most commonly used for land cover classification, although cloud cover is a problem (AKIYAMA and KAWAMURA, 2003). Synthetic aperture radar (SAR) is well suited for observing cloud-covered forests in the tropics because it uses longer wavelengths that pass through clouds (OUCHI, 2009). Therefore SAR images are worth to use to monitor forests in the tropics (ROSENQVIST et al., 2003, AlmEIDA-FilHo et al., 2007).

Estimating decrease of forest biomass is important to understand the impacts of deforestation on carbon emissions. SAR, which observes land surface using a longer wavelength, such as the L-band $(15-30 \mathrm{~cm})$, has a higher capability of detecting biomass in forests than X-band $(2.4-3.75 \mathrm{~cm})$ and C-band $(3.75-7.5 \mathrm{~cm})$ SAR due to scattering of the emitted signal from SAR within canopies (OUCHI, 2009). Phased Array type L-band Synthetic Aperture Radar (PALSAR) on the Advanced Land Observing Satellite (ALOS) is expected to be useful for biomass estimation of forest (ROSENQVIST $e t$ al., 2007). The relationship between forest biomass and signal (backscattering coefficients) of L-band SAR was examined by many scientists for these two decades (SENOO et al., 1995; LUCKMAN et al., 1997; LUCKMAN et al., 1998; CASTELA et al., 2002; LuCAS et al., 2006). Although the longer wavelength of L-band among space-borne SAR has an advantage in higher saturation levels to biomass than X-band or C-band SAR, signals are saturated at dry biomass between 50 and $150 \mathrm{Mg}^{-1}$ (LUCKMAN et al., 1998, CASTELA et al., 2002, LE TOAN et al., 2004; LUCUS et $a l ., 2006)$. Forest structure causes variation in backscattering coefficients and its saturation level (CASTELA et al., 2002). In addition, wood materials on the ground after deforestation function as corner reflectors and cause an initial increase in the L-band SAR backscatter, which then subsequently decreases over time as the wood decays (ALMEIDA-FiLHo et al.,
2007).

Double bounce

Input microwave signal scatters isotropically in canopies by leaves, branches and stems which locate randomly. Therefore microwaves scattered to various directions and a small part of input energy returns to SAR (Fig. 1). This type of scattering is called volume scattering. Backscattering is dominated by the scattered signal from branches and stems but not forest floor in mature forest in L-band SAR. Reflection of the like polarization with that of input signal (HH or VV) dominates for the case of natural objects, however cross polarization ( $\mathrm{HV}$ or $\mathrm{VH}$ ) signal occurs, which is called depolarization, in canopies (IGUCHI, 1992). HV indicates the horizontal transmit $(\mathrm{H})$ and vertical receive $(\mathrm{V})$ radar channel and so on.

On the contrary, specular reflection is major at flat smooth surface, and it results in return signals of the same polarization. When a microwave is reflected by a smooth surface such as still-water surface and then by a smooth objects such as tree stems (or vice versa), it is called double bounce (IGUCHI, 1992, Fig. 1). Since the direction of the reflected signal is focused, the backscattering amplitude is greater than that of volume scattering. Double bounce by the interaction of trees and ground is the greatest where trees with large stems grow on flat smooth ground like still-water surface. The return signal of the same polarization such as $\mathrm{HH}$ is increased by double bounce, since specular reflection dominates (IGUCHI, 1992). For example, the HH signal is increased by fallen tree stems after forest fires as well as after

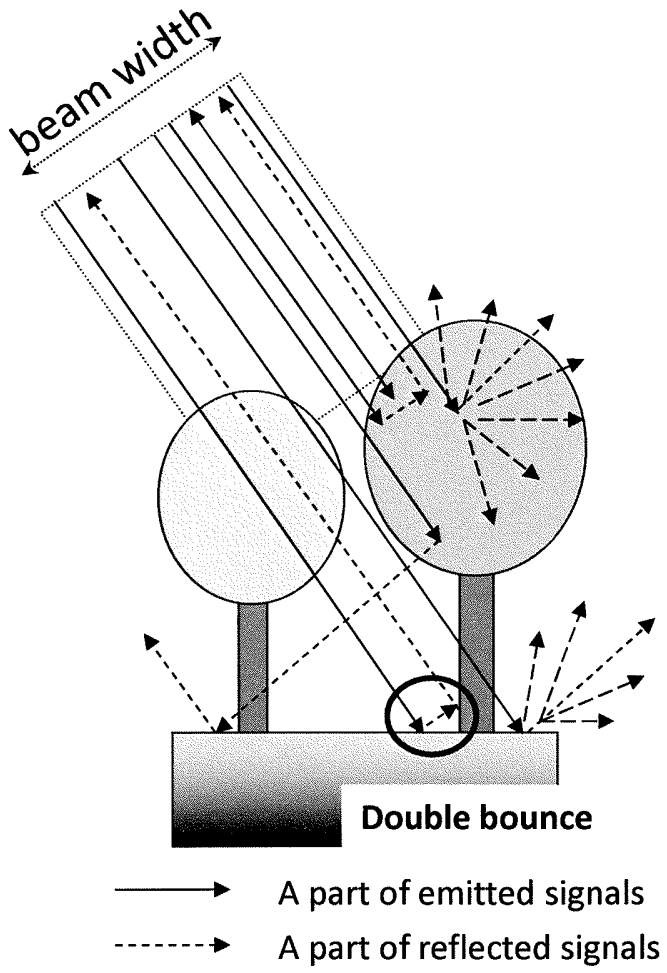

Fig. 1 Schematic description of scattering of SAR signal. Double bounce is returned signal reflected by both the ground or water surface and tree stems. 
deforestation (Almeida-FilHo et al., 2007), and the HH signal is also increased by open swamp forest under submerged conditions (AZIZ and WHITE, 2003). Areas with double bounce have relatively greater BSC in $\mathrm{HH}$ than $\mathrm{HV}$ compared with areas without double bounce. On the other hand, double bounce is negligible for dense forests even under submerged conditions, because BSC of $\mathrm{HH}$ and $\mathrm{HV}$ was quite stable through dry and submerged conditions, and because BSC was smaller than it was in open canopy forests, as described below.

The objective of this study was to evaluate the usefulness of PALSAR imagery performance of backscatter signals for biomass estimation to monitor peat swamp forests. A simple method was developed to reduce the effects of double bounce on the backscattering coefficient (BSC), and above ground biomass (AGB) estimation models were developed using the original and corrected BSC using a curvilinear regression method. AGB was estimated using the original and corrected $\mathrm{BSC}$, and the two results were compared to evaluate the usefulness of the correction for monitoring seasonal and interannual forest changes in a peat swamp forest.

\section{STUDY SITE AND DATA}

The study site was the south of Palagka Raya, Central Kalimantan, Indonesia. The natural vegetation of the area is peat swamp forest. In 1995, 1.7 million hectors of the forest was chosen to be developed as paddy fields by the Mega Rice Project (MUHAMAD, 2001) to increase domestic rice supply. The project was to start at the end of 1995 and to be completing in 2005. Many drainage channels were dug between 1996 and 1999. Then the project was abandoned for various reasons including the Asian economic crisis and forest fire. However, the drainage is continuing and the peat swamp is drying. In addition, the channel allowed easy access, resulting in illegal deforestation. The dried peat burns easily and much time is needed to extinguish the fires. Thus the peat swamp forest was in critical condition.

A field survey was conducted between 2008 and 2010 and thirty-one plots with an area of 40 meters by 30 meters were set in shrublands and in open and closed forests. Stem diameter at breast height $(1.3 \mathrm{~m}, \mathrm{DBH})$ of all trees were measured with a tape measure. Tree height was measured with a Vertex (Haglöf, Sweden). A DBH-Height curve was derived in each plot and tree height was estimated using the DBH-Height curve for all trees. The above ground biomass of each tree was computed with the equation (modified from KrYONO et al., 2006).

$\mathrm{AGB}=2.17 \times \mathrm{BA}^{1.02} \times \mathrm{WD}^{0.978} \times \mathrm{H}^{0.631}$

where AGB is above ground biomass ( $\mathrm{kg}), \mathrm{BA}$ is basal area $\left(\mathrm{m}^{2}\right)$, WD is wood density $\left(\mathrm{Kg} \mathrm{m}^{-2}\right)$ and $\mathrm{H}$ is tree height (m). The basal area was computed using DBH assuming circular stems. The plot locations were measured using a handheld GPS (Model 60CSX, Garmin International, Inc. KS, USA). AGB per hector in each plot was computed using the measurements.

For this study, we used five PALSAR images of Fine Beam Double Polarization mode that were taken on five days (July 9, 2007, October 9, 2007, May 26, 2008, October 14, 2009 and December 2, 2010). Hereafter, these dates are referred to $0707,0710,0805,0910$ and 1012, respectively. For example, PAL0707 shows the PALSAR image of July 9, 2007, and HV0710 is the horizontal transmit $(\mathrm{H})$ and vertical receive (V) radar channel (HV) of image obtained on October 9, 2007. In general, the radar backscatter is modulated by the terrain height variation. Among the radar backscattering coefficients, gamma-naught, which is the normalized-radar-cross-section divided by the cosine of local incidence angle is the most insensitive parameter to the terrain effect as well as to the offnadir angle. Thus, we adopted gamma-naught for this analysis and used the slope-corrected, ortho-rectified, and geo-coded PALSAR images by JAXA (SHIMADA, 2010). All PALSAR images were averaged by an average filter with a 7 by 7 pixel kernel to reduce speckle noise.

\section{METHODS}

We found that the effect of double bounce was outstanding in submerged forest and fire scars with fallen trees during a preliminary study. Therefore, correction of double bounce effect was attempted for HV images and the results were compared with the original HV images. AGB was estimated using the original and corrected PALSAR images and the results were compared. The procedure was as follows.

Correction of Double Bounce Effect

\section{Assumption and correction}

While double bounce is dominant in submerged forests and burnt forests, multiple scattering is dominant in dry land forests. Since backscattering is greater in submerged and burnt forest than in peat swamp forest, $\mathrm{HH}$ and HV BSC disperses in a scattergram as shown in Fig. 2 using PAL0707.

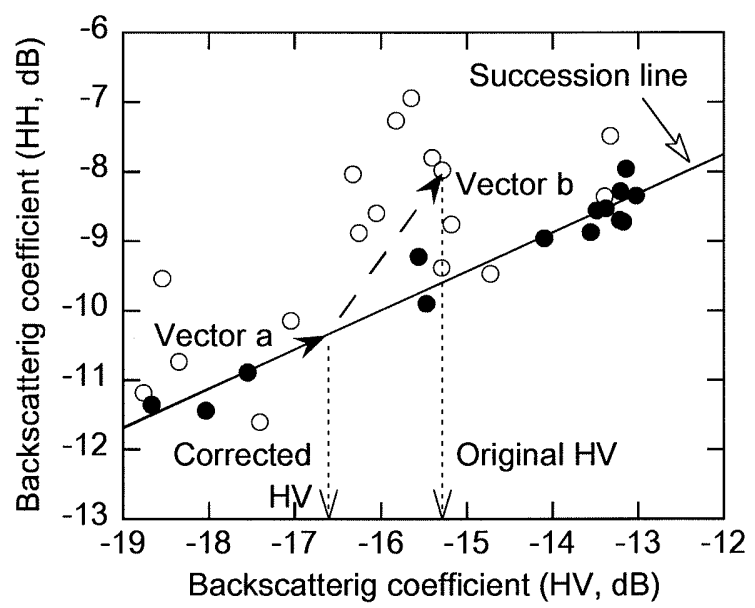

Fig. 2 Scatter diagram of $\mathrm{HH}$ and $\mathrm{HV}$ backscattering coefficient in plot areas on PAL0707.

Black circles are plots commonly appeared along the succession line in all PALSAR images, which suggests the vegetation condition is similar within 4 years. Most plots with open circles have relatively greater backscattering coefficient (BSC) of HH than the plots with black circle. The higher BSC in HH was probably caused by the double bounce by the surface condition. 
Black circles are plots commonly appeared at the bottom of plots' distribution, which have lower BSC of $\mathrm{HH}$ among plots with similar BSC of HV, in all PALSAR images. This suggested that the vegetation condition was similar within 4 years in these plots. Areas suffered by double bounce show greater HH BSC than HV BSC as shown in Fig. 2 with some of open circles. On the contrary, a linear relationship would exist between HH and HV BSC among wildland and forest plots with black circles. Plots with smaller biomass have smaller BSC, and plots with greater biomass have greater BSC in the linear relationship. The relationship can be expressed by a line, and intensity of BSC would show succession stage of wild vegetation (succession line). The succession line (2) can be determined by a linear regression analysis using BSC of 14 plots with black circles which were located at the lowerright edge in Fig. 2. These plots also had similar BSC in other images.

$$
\mathrm{HH}_{\text {org }}=-1.023+0.5611 \times \mathrm{HV}_{\text {org }} \mathrm{R}^{2}=0.951
$$

where $\mathrm{HV}_{\text {org }}$ and $\mathrm{HH}_{\text {org }}$ are $\mathrm{BSC}$ of $\mathrm{HV}$ and $\mathrm{HH}$ in the original PAL0707, respectively.

The regression line shows that BSC of HV, which is caused by depolarization (IGUCHI, 1992), increased by canopy growth. The slope shows BSC of HV increased about twice of BSC of $\mathrm{HH}$.

Double bounce, which is specular reflection of SAR signal twice (IGUCHI, 1992) on the flat water surface or fallen tree stems at first and next on stems in the test site, dominates and returns strong signals to SAR. Specular reflection doesn't cause depolarization, therefore BSC increases much greater in $\mathrm{HH}$ polarization than $\mathrm{HV}$ polarization. Thus specular reflection, by which most signals are reflected to one direction without depolarization (IGUCHI, 1992), is dominant in submerged forests and open areas with fallen stems. On the contrary, Lambertian reflection, by which signals are scattered isotropically and depolarization occurs (IGUCHI, 1992), is dominant in dryland forests.

As for ground condition, if the ground surface is smooth like still-water under swamp forest, specular reflection is dominant on the ground (YAMAGUCHI, 2001) and causes strong double bounce. On the other hand, if the ground surface is rough like soil ground with bush, Lambertian reflection is dominant (YAMAGUCHI, 2001) and double bounce is very small. This means that contribution of double bounce changes in the peat swamp forest due to changing water level.
As described above, the dominant reflection is different in submerged forest and fire scars from dryland forest, we assume that the submerged water and fallen tree stems (smooth elements) yields contribution on BSC inversely to dry land forest, since BSC of $\mathrm{HH}$ is enhanced by double bounce greatly. It is expressed as the ratio of $\mathrm{HH}$ and HV BSC to be 1.782 to be the inverse of the regression slope of 0.5611 in equation (2).

$$
\mathrm{HH}_{\text {org }}=1.782 \times \mathrm{HV}_{\text {org }}+\mathrm{C}
$$

where $\mathrm{C}$ is a constant which is determined by BSC of each pixel.

We considered two vectors, one caused by stems (vector a) and the other caused by the double bounce (vector b, Fig 2.). Since BSC caused by the double bounce is a noise factor when we analyze biomass using BSC, we reduced the double bounce effect as follows.

1. We supposed the succession line showed changes of BSC by an ideal tree growth. If biomass was greater, BSC became greater along the succession line (succession vector a).

2. On the other hand, smooth water surface and fallen stems cause changes in BSC inversely to the succession line due to the double bounce effect (disturbance vector $\mathrm{b}$ ).

3. We assume that BSC was a linear combination of the succession and disturbance vectors. Therefore intersection of the succession line and disturbance vector of each pixel shows a HV BSC value which was contributed mainly by canopy elements. We define the HV BSC at the intersection as the corrected HV BSC from the double bounce effect.

The corrected $\mathrm{HV}$ was computed for all images using the succession line (vector a) in equation (2) and vector $b$ (3) for the filtered images.

\section{Comparison of Seasonal Trend of BSC}

Five reference areas representing four categories of land were selected: two mature forests with high AGB (High AGB forest 1 and 2), a forest along Kahayan river (Riverside forest), a fire scar burnt around 2003 (Fire scar) and mature forest burnt in 2009 (Burnt forest) (Table 1). We visited all areas in 2008, 2009 or 2010, however we couldn't measure biomass in Riverside forest and Burnt forest before the fire in 2010. Therefore biomass of these categories is based on our visual inspection with stand height etc. BSC values were picked up from the five images, and seasonal trend of BSC was

\begin{tabular}{|c|c|}
\hline Category & Description \\
\hline High AGB forest 1 & $\begin{array}{l}\text { This forest was located within a peat swamp forest with AGB } \\
\text { between } 180 \text { and } 300 \mathrm{Mg} \text { ha }{ }^{-1} \text { without serious disturbance. Crown } \\
\text { closure varies area by area. }\end{array}$ \\
\hline High AGB forest 2 & Location was very close to High AGB forest 1 within the same forest. \\
\hline Riverside forest & $\begin{array}{l}\text { This forest located along Kahayan river. AGB might be less than } 150 \\
\mathrm{Mg} \text { ha }^{-1} \text { by our visual inspection. }\end{array}$ \\
\hline Fire scar & $\begin{array}{l}\text { Tree stems were laid down on the ground and aliving biomass was } \\
\text { about } 6 \text { to } 20 \mathrm{Mg} \mathrm{ha}^{-1} \text { in } 2008 \text {. The fire scar was clearly identified on } \\
\text { PAL0707. }\end{array}$ \\
\hline Burnt forest & $\begin{array}{l}\text { Forest near High AGB forest } 1 \text { was burnt in October } 2009 \text {. AGB } \\
\text { might be about } 150 \mathrm{Mg} \text { ha }{ }^{-1} \text { less than that of High AGB forest before } \\
\text { the fire. Tree stems fell over after the fire. }\end{array}$ \\
\hline
\end{tabular}

Table 1 Description of selected reference areas 
compared among the five categories for original $\mathrm{HH}$, original $\mathrm{HV}$ and corrected $\mathrm{HV}$ on figures.

Biomass Estimation and Monitoring

Field plots were separated into two groups according to the succession line (Fig. 2). Plots for succession line were used for creating a biomass estimation model and others are used for validation. Regression models were developed between above ground biomass (AGB, $\mathrm{Mg} \mathrm{ha}^{-1}$ ) and original or corrected HV BSC by a curvilinear regression method using AGB of 14 plots and the filtered PAL0707 as follows.

$$
\begin{array}{ll}
\mathrm{AGB}_{\text {org }}=3.585 \times 10^{5} \times \mathrm{e}^{0.5994 \mathrm{HV} \text { org }} & \mathrm{R}^{2}=0.4923 \\
\mathrm{AGB}_{\text {cor }}=3.204 \times 10^{5} \times \mathrm{e}^{0.5918 \mathrm{HV} \text { cor }} & \mathrm{R}^{2}=0.4746
\end{array}
$$

The performances of these two models were validated using data from the 17 plots that were not used for modeling. Equation (4) was applied to the original HV images and the equation (5) was applied to the corrected HV images.

ERDAS IMAGINE version 9.3 (ERDAS Inc., USA) was used for image processing and KaleidaGraph version 4.0 (Synergy Software, USA) was used for statistical analysis.

\section{RESULTS AND DISCUSSION}

Temporal Change of Backscattering Coefficient (BSC)

Data range of $\mathrm{HH}$ BSC (ca. $5 \mathrm{~dB}$ ) was wider than that of HV BSC (ca. $3.5 \mathrm{~dB}$ ) of the original images regarding the selected categories (Fig. 3 a, b, Table 1). BSC was obviously greater in Fire scar than that in High AGB forest 1 and 2 in all $\mathrm{HH}$ images. On the other hand, Fire scar had low biomass (about 6 to $20 \mathrm{Mg} \mathrm{ha}^{-1}$ ), while High AGB forests had a much greater biomass (about 180 to $300 \mathrm{Mg} \mathrm{ha}{ }^{-1}$ ) than that. The difference in BSC and AGB was apparent in Burnt forest with about $150 \mathrm{Mg}$ ha ${ }^{-1}$ of AGB between before and after a forest fire (Fig. 3a). Fallen stems without burning overlapped each other and few trees stood on the ground in Burnt forest after the fire. The sharpe increase of BSC (about $6 \mathrm{~dB}$ ) suggests that fallen stems had a greater influence on BSC than tree canopies in $\mathrm{HH}$. While BSC dropped about $1.5 \mathrm{~dB}$ as a result of the fire and increased about $2 \mathrm{~dB}$ later in the original HV (Fig. $3 \mathrm{~b})$. The change was rather small comparing with the change in HH. BSC of the original HV images in Fire scar was greater than that in High AGB forests by May 2008, then it became smaller than High AGB forests (Fig. 3b). Similar changes were reported in the case of forest logging (ALMEIDA-FiLHo et $a l ., 2007)$. The original $\mathrm{BSC}$ of $\mathrm{HH}$ and $\mathrm{HV}$ images changed considerably with season in fire scars suggesting that BSC in fire scars were easily affected by environmental conditions such as water content as described in AKrYAMA et al. (2007).

The trees in Riverside forest were short and Riverside forest would have less biomass than High AGB forests by our visual inspection, although BSC was greater in Riverside forest than High AGB forests in the original $\mathrm{HH}$ and HV images. The difference was greater in $\mathrm{HH}$ images than $\mathrm{HV}$ images. This is consistent with the finding that the double bounce effect is greater in HH signals than HV signals (AZIZ and WHITE, 2003).
Water level change would cause seasonal or inter-annual variation of BSC especially at the time of high water level under flood conditions as occurred in December 2010. Unlike

a)

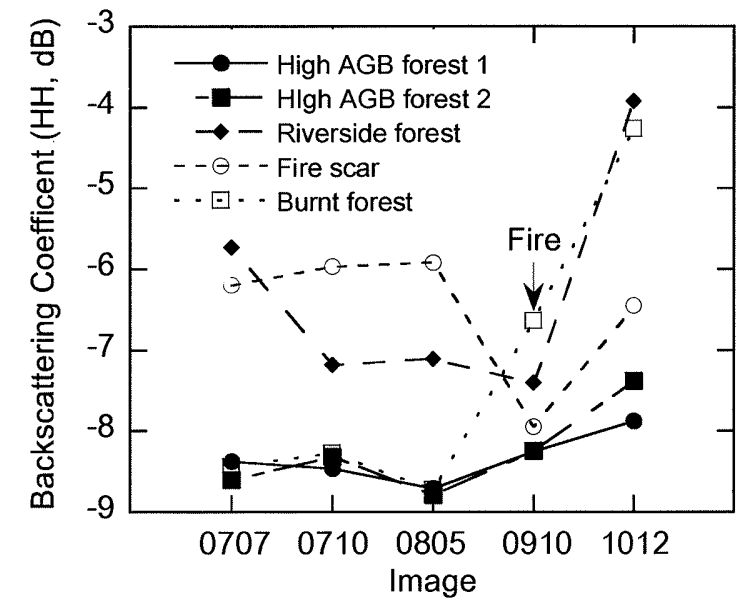

b)

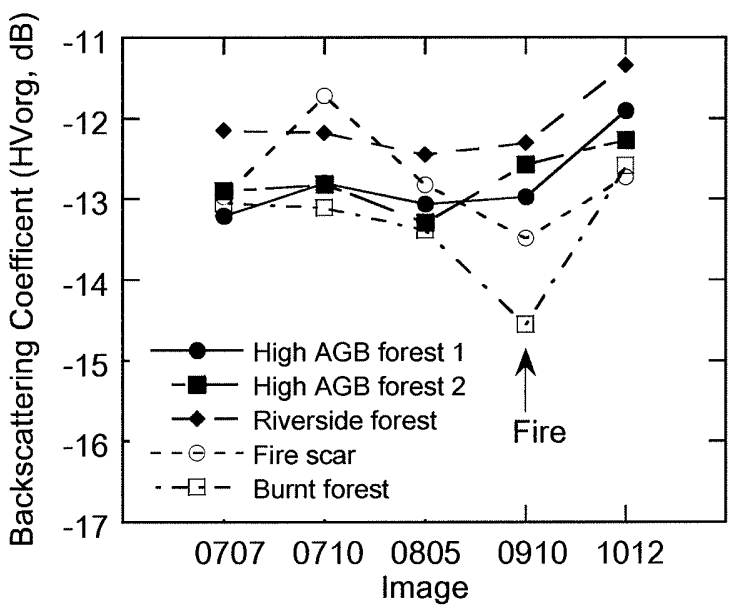

c)

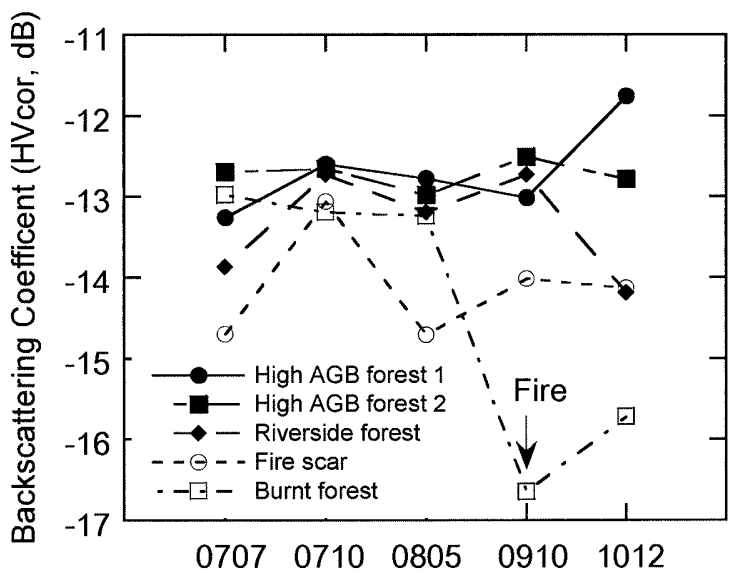

Fig. 3 Seasonal trend of BSC

Seasonal changes of BSC are drawn for the selected categories in Table 1. 
Riverside forest, BSC of $\mathrm{HH}$ was most stable in High AGB forests among the land cover categories in all images. These evidences were caused by the difference of double bounce effects on these two forest types caused by whether dense forest with large biomass or not (AZIZ and WHITE, 2003).

The double bounce correction reduced this inconsistency in $\mathrm{HV}$ images especially for Riverside forest, and the order of BSC intensity coincided with AGB quite well (Fig. 3b). However, the correction may not work well on HV1012, since the data range of forest categories (High AGB forest 1 and 2, Riverside forest) became wider than that of original $\mathrm{HV}$. The succession line was determined using PAL0707 alone and was applied to all images, although the succession line might change due to environmental conditions in each image.

Relationship between AGB and BSC

Although a curve-linear relationship has been reported between BSC and above ground biomass in the literature (LUCKMAN et al., 1997; LUCKMAN et al., 1998; CASTELA et al., 2002; LE TOAN $e t$ al., 2004; LUCAS $e$ al., 2006), the relationship was not clear if all plots are considered in Fig. 4. In Fire scars, standing AGB was low although BSC was greater than that of closed forests due to double bounce by fallen trees (Fig. 3 ), similar to the case of deforestation (ALmEIDA-FilHo et al., 2007). Therefore Fig. 4 doesn't show a general relationship between standing AGB and BSC, which is expected under ordinary conditions as shown in the literature (LUCKMAN $e t$ al., 1997; LUCKMAN et al., 1998; CASTELA et al., 2002; LE TOAN et al., 2004; LuCAS et al., 2006). Therefore, plots along the succession line (Fig. 2), which are shown as black circles in Fig. 4, were selected for the regression analysis to develop an AGB estimation model. The curve shows the relationship between AGB and BSC in the original HV images of the selected plots (Fig.4). BSC tended to become saturated with increasing AGB (Fig. 4), which caused inaccurate biomass estimation in high biomass forests.

Biomass estimation models were developed using the

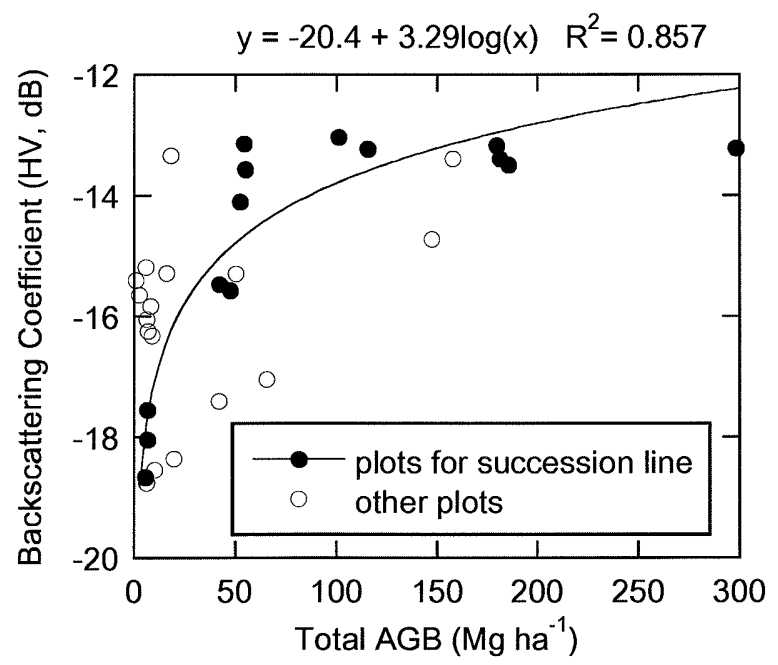

Fig. 4 Relationship between AGB and BSC

Relationship between AGB and BSC was examined using the original HV0707. selected 14 plots for original and corrected HV0707 (Fig. 5). The models were barely different between the original HV (Fig. 5a) and the corrected HV (Fig. 5b), probably because the double bounce effect in the selected plots was small. The models diverged when BSC was greater than about $-14 \mathrm{~dB}$. The estimated biomass exceeding $100 \mathrm{Mg}^{-1}$ wouldn't be reliable due to the divergence.

\section{AGB estimation}

The relationship between measured and estimated AGB

a)

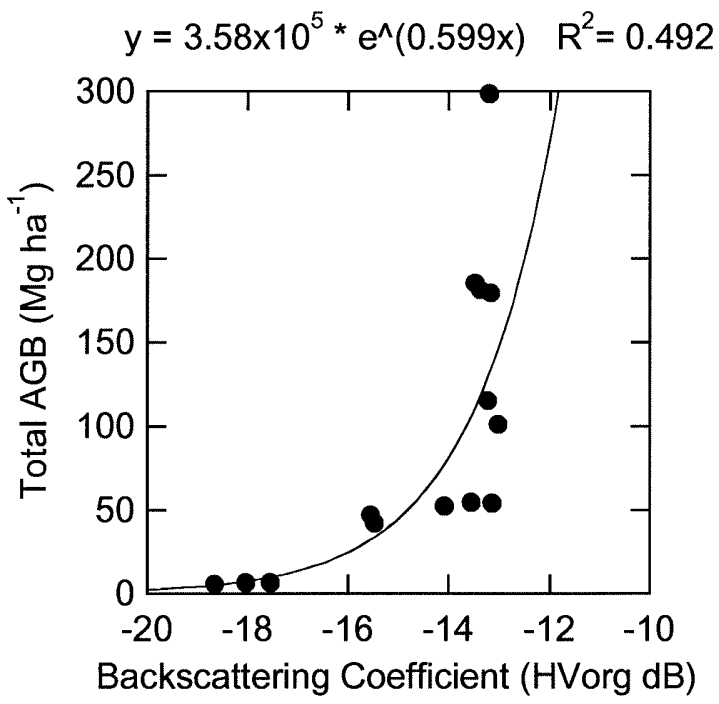

b)

$$
y=3.20 \times 10^{5} * e^{\wedge}(0.592 x) \quad R^{2}=0.475
$$

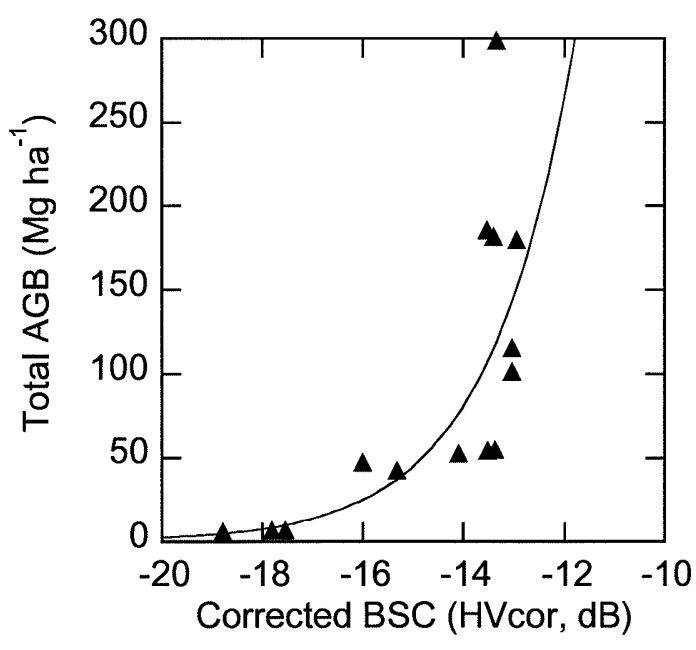

Fig. 5 Biomass estimation models Two Biomass estimation models were determined by a curviliner regression fitting, one for the original HV image (a) and the other for the corrected HV image (b) using HV0707. 
is shown in Fig. 6. Correlation coefficients adjusted for the degree of freedom were $0.439(t=1.893$, insignificant at $5 \%)$ for the original HV and 0.728 ( $t=4.111$, significant at $1 \%)$ for the corrected HV. The root mean square errors (RMSE) between the field and estimated AGB were $31.3 \mathrm{Mg} \mathrm{ha}^{-1}$ and $22.0 \mathrm{Mg} \mathrm{ha}^{-1}$ for the original and corrected $\mathrm{HV}$, respectively. As appeared in RMSE, plots concentrated along the regression line after the double bounce correction (Fig. 6). Thus the double bounce correction improved AGB estimation, however the slope was quite smaller than 1 due to saturation of the backscattering.

The biomass estimation models in equations (4) and (5) were applied for the original HV and corrected HV images,

a)

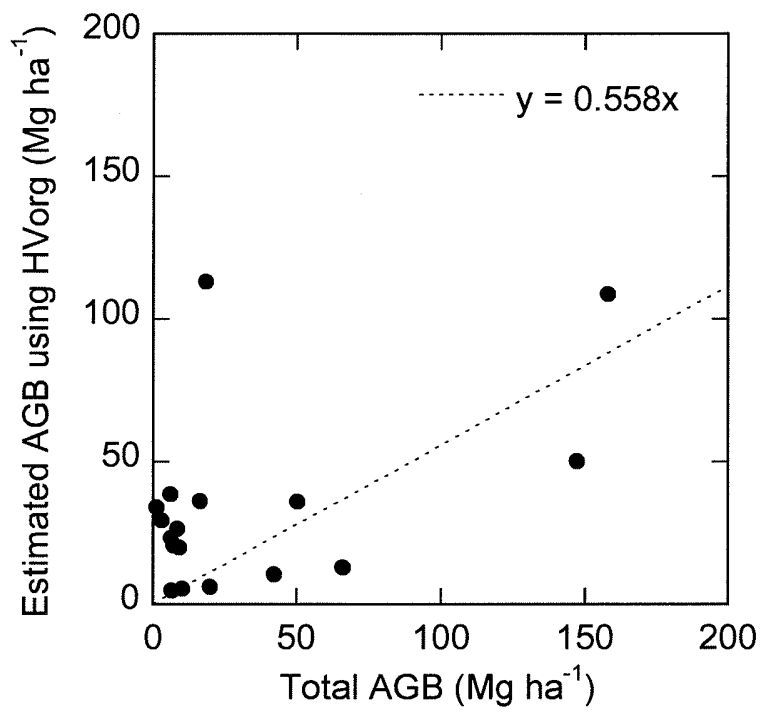

b)

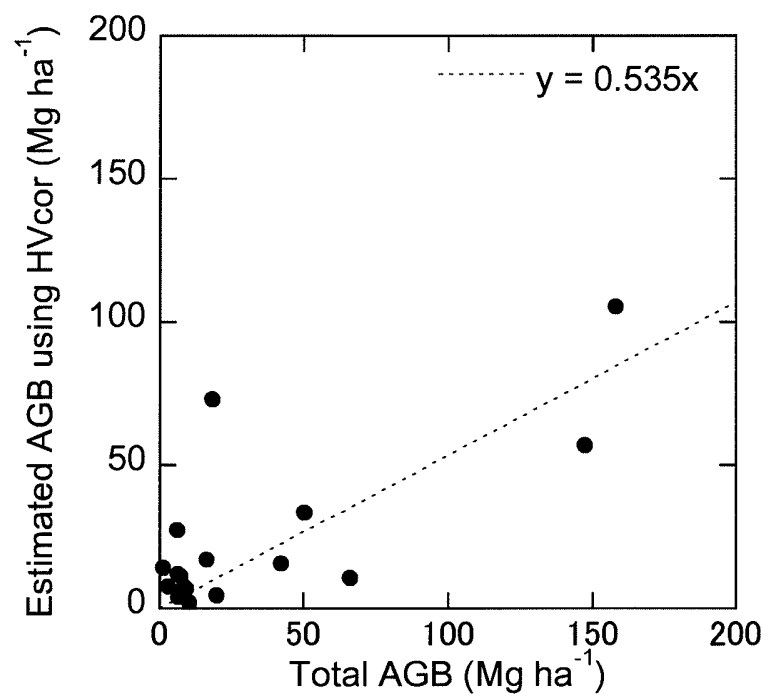

Fig. 6 Validation of biomass estimation

Relationship between field and estimated AGB was examined for the original $\mathrm{HV}$ image (a) and the corrected HV image (b) using HV0707. respectively. Fig. 7 shows the estimated AGB for the selected categories in Table 1. AGB was estimated greater consistently in Riverside forest than that in the two High AGB forests using the original HV (Fig. 7a). AGB changed drastic in Fire scar especially at October 2010. On the other hand, AGB was estimated smaller consistently in Riverside forest than High AGB forest 2 using the corrected HV (Fig. 7b). Although the estimated AGB was quite stable for High AGB forest 2, AGB changed greatly in December 2010 for High AGB forest 1 . The difference suggests non-uniform BSC in forests in HV1012 and the effect of divergence in Fig. 5. BSC was probably influenced in a large area by submerging in PAL1012, therefore, the succession line would be determined using BSC of PAL1012. The steady estimated AGB of High AGB forest 2 in all cases (Fig. $7 \mathrm{~b}$ ) probably suggests, if the succession line determined properly for each scene, accuracy of AGB estimation would

a)

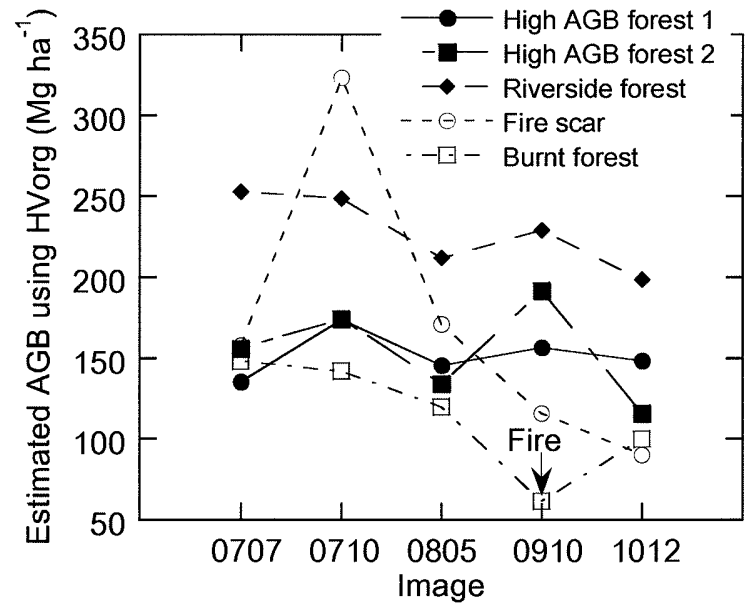

b )

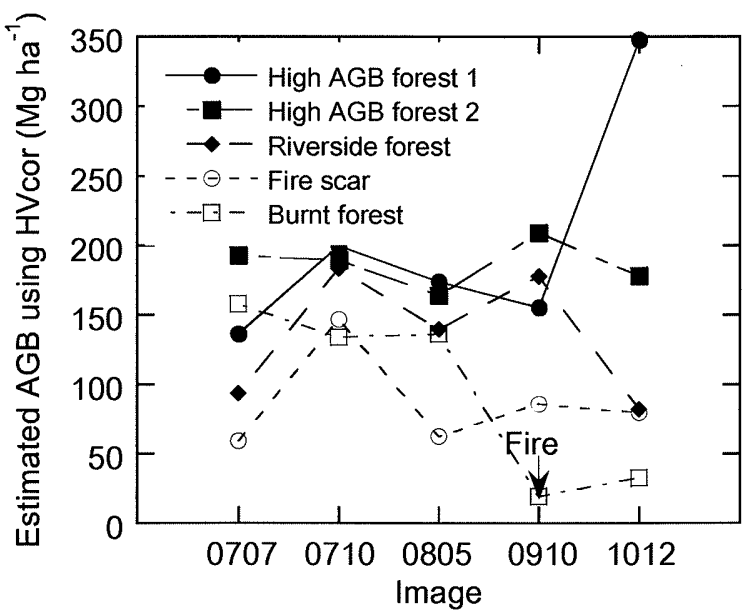

Fig. 7 Seasonal trend of estimated AGB

Estimated AGB was compared seasonally for the selected categories in Table 1 for the original HV images (a) and the corrected $\mathrm{HV}$ images (b). 
improve. As for Burnt forest, the AGB was estimated reasonably in October 2009 and December 2010. Thus the double bounce correction reduced the overestimation of AGB in Fire scar and Riverside forest.

Spatial distribution of AGB appeared differently between the results using the original HV (Fig. 8a) and the corrected HV (Fig. 8b). AGB appeared properly in shrub or grass areas where AGB was less than $50 \mathrm{Mg} \mathrm{ha}^{-1}$ in all images with or without the double bounce correction. PAL0910 was obtained under dry conditions when forest fire occurred, and some fire scars appeared in the middle of image in red on PAL0910 (Burnt forest, Fig. 8a). Double bounce by fallen stems caused the overestimation of AGB. PAL1012 was obtained under wet conditions when the ground filled with water in a large part of forest, bush and grass. The submerged condition greatly increased the double bounce effect and overestimation of AGB using the original HV especially in areas over $300 \mathrm{Mg} \mathrm{ha}^{-1}$ of estimated AGB. According to our forest survey, AGB rarely exceeded $300 \mathrm{Mg} \mathrm{ha}^{-1}$ in the forest which appeared in the middle bottom in each plate of Fig. 8 . Therefore, in a large part

1)
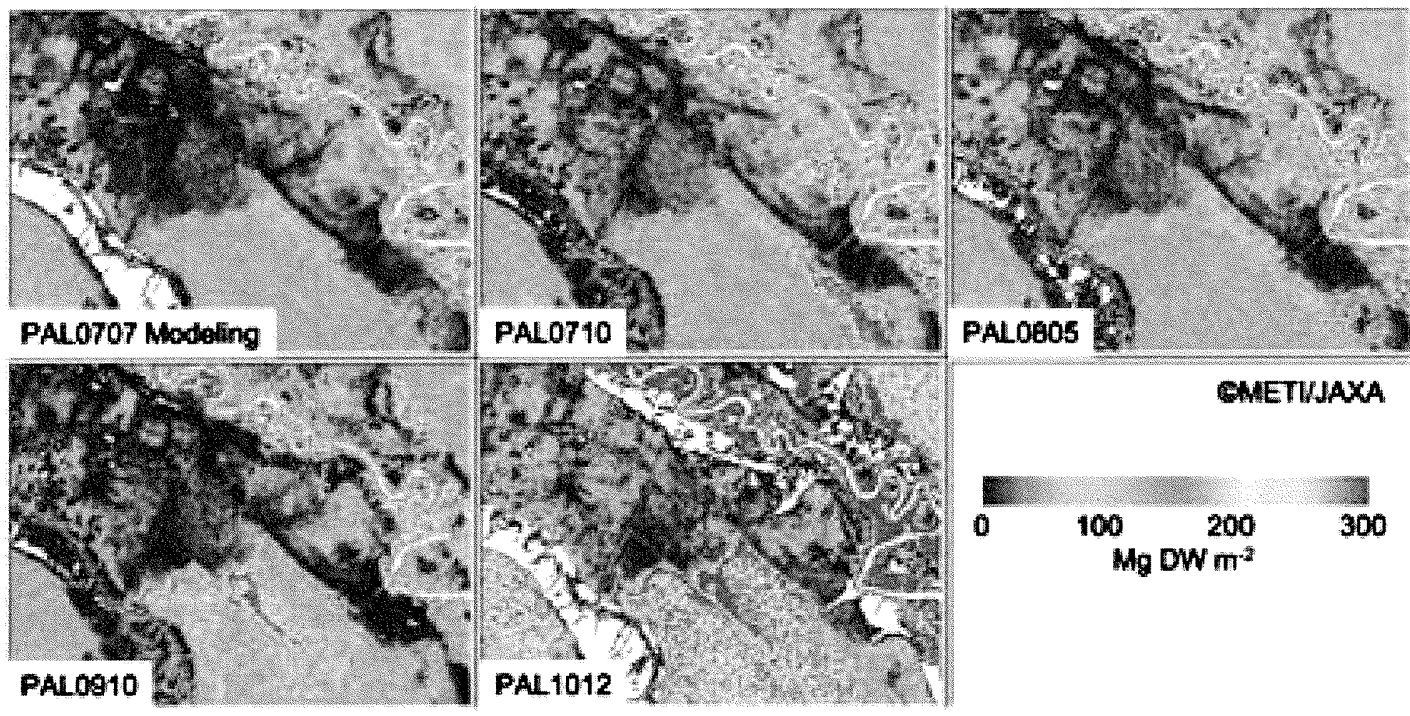

b)
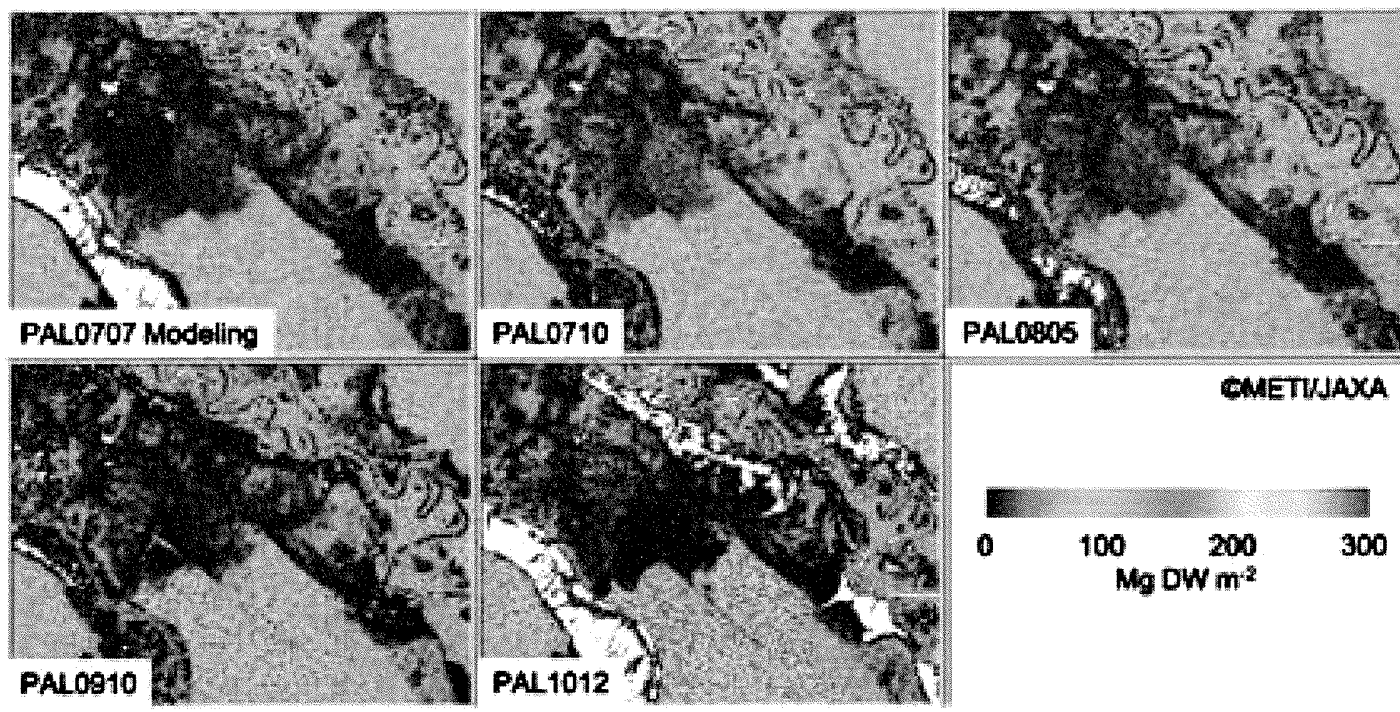

Fig. 8 Distribution of estimated AGB in different seasons

Estimated AGB was mapped and its seasonal change was examined for the original $\mathrm{HV}$ images (a) and for the corrected HV images (b). 
of the areas with $\mathrm{AGB}$ over $300 \mathrm{Mg} \mathrm{ha}^{-1}$ (Fig 8a), the AGB was overestimated as a result of double bounce and the divergence of biomass estimation model (Fig. $5 \mathrm{a}$ ).

The white areas in Fig. 8 are areas of open water, where AGB was not estimated. Of the five images, PAL1012 had the largest the open water area. As for riverside of Kahayan at the upper right corner (Fig. 8), AGB was estimated rather steadily except PAL1012. AGB was estimated at over $300 \mathrm{Mg}$ ha $^{-1}$ in forests along the river (Fig. 8a), however the double bounce correction reduced the overestimation and was successful in this area (Fig. 8b). Regarding natural forest in the middle bottom (High AGB forests), AGB also appeared similarly among the images except PAL1012. As for fire scars, the corrected HV improved AGB estimation in areas with fallen trees by reducing double bounce in October 2009 and December 2010 (Fig. 8b). However, the estimated AGB using HV1012 was higher than those in other images in natural forests at the bottom. The reason for the higher estimation of AGB in December 2010 was not clear. As described previously, large parts of the forest would be submerged and double bounce might be the cause of overestimation of AGB even after the correction.

Although the AGB distribution maps using original HV images (Fig. 8a) showed high AGB in fire scars with fallen trees and riverside forests under submerged condition especially in PAL1012, such anomalies were reduced greatly using the corrected HV images. The AGB distribution pattern became quite similar among maps and the overestimation of AGB was corrected reasonably as described previously (Fig. $8 b)$. The improvement demonstrates the usefulness of the double bounce correction in fire scars with fallen trees and open forest under submerged condition.

\section{CONCLUSIONS}

Effect of double bounce, which was caused by smooth water surface in submerged forest and fallen tree stems in burnt forest, is greater on $\mathrm{BSC}$ of $\mathrm{HH}$ than that of $\mathrm{HV}$ of PALSAR imagery. Biomass is overestimated for these areas due to double bounce even using HV data. The method of reducing double bounce effects developed in this research greatly reduced the overestimation of AGB. Comparisons of estimated AGB among five PALSAR images showed that the estimated AGB became more accurate. However estimates of AGB in mature forests were not so accurate when AGB exceeded $100 \mathrm{Mg} \mathrm{ha}^{-1}$ due to the saturation of BSC in High AGB forests. The double bounce correction can be used to monitor growth or regrowth of disturbed forest or deforestation in peat swamp forest using PALSAR imagery.

\section{ACKNOWLEDGEMENTS}

The field works were conducted by a team of Centre for International Co-operation in Sustainable Management of Tropical Peat (SIMTROP), University of Palangka Raya, and Forestry and Forest Products Research Institute (FFPRI) approved by the State Ministry of Research and Technology (RISTEK), Indonesia. The authors appreciate for the support of field surveys by the staff members of University of Palangka
Raya. The study was executed as part of the research program (A-0802) supported by the Global Environment Research Fund of the Ministry of the Environment, Japan.

\section{LITERATURE CITED}

Akiyama, T., KaWAmura, K. (2003) Study of cloud cover ratio of Landsat-5 for the application on agriculture and forestry. Journal of the Japan Society of Photogrammetry and Remote Sensing, 42(3):29-34 (in Japanese with English summary)

Akiyama, T., Ishitsuka, N., Ogawa, S., Okamoto, K., Saitoh, G., UCHIDA, S. (2007) Handbook of Agricultural Remote Sensing. The Japanese Agricultural Systems Society, Tokyo, 512pp (in Japanese)

Almeida-Filho, R., Rosenqvist, A., Shimabukuro, Y. E., Silva-Gomez, R. (2007) Detecting deforestation with multitemporal L-band SAR imagery: a case study in western Brazilian Amazônia. Int. J. Remote Sensing, 28(6):1383-1390

AzIZ, H.K., WHITE, K. (2003) Using MIMICS to model L-band SAR backscatter from a peat swamp forest. Journal of Tropical Forest Science, 15(4):546-556

Castela, T., Guerrab, F., Caraglioa, Y., Houlliera, F. (2002) Retrieval biomass of a large Venezuelan pine plantation using JERS-1 SAR data. Analysis of forest structure impact on radar signature. Remote Sens. Environ., 79:30-41

DeFries, R., Achard, F., Brown, S., Herold, M., Murdiyarso, D., Schlamadinger, B., SouzA C. Jr. (2007) Earth observations for estimating greenhouse gas emissions from deforestation in developing countries. Environmental Science and Policy, 10:385394

IgUchI, Y. (ed.) (1992) Synthetic Aperture Radar (SAR). Earth Remote Sensing Data Analysis Center, Tokyo, 369pp. (in Japanese, The title is authors' tentative translation.)

IPCC (2007) Climate Change 2007: The Physical Science Basis. Contribution of Working Group I to the Fourth Assessment Report of the Intergovernmental Panel on Climate Change. [Solomon, S., Qin, D., Manning, M., Chen, Z., Marquis, M., Averyt, K.B., Tignor, M., and Miller, H.L., (eds.)] Cambridge University Press, Cambridge, United Kingdom and New York, NY, USA, 996 pp (Chapter 7 499-587)

Kryono Y., Prajadinata S., Oo M.Z., Oosumi Y. (2006) Development of the simplified methodologies for measuring and predicting biomass carbon stock. In: Fiscal report of forestation basic data collection aiming at small-scale environmental planting, CDM project, 2005. Forestry and Forest Products Research Institute, Tsukuba, pp 8-41 (in Japanese)

Le Toan, T., Quegan, S., Woodward, I., Lomas, M., Delbart, N., PICARD, G. (2004) Relating radar remote sensing of biomass to modelling of forest carbon budgets. Climatic Change, 67: 379-402 Lucas, R.M., Cronin, N., Lee, A., Moghaddam, M., Witte, C., Trckle, P. (2006) Empirical relationships between AIRSAR backscatter and LiDAR-derived forest biomass, Queensland, Australia. Remote Sens. Environ., 100:407-425

Luckman, A., Baker, J., Kuplich, T.M., Yanasse, C.C.F., Frery, A.C.(1997) A Study of the relationship between radar backscatter and regenerating tropical forest biomass for spaceborne SAR instruments. Remote Sens. Environ., 60:1-13

LUCKMAN, A., BAKER, J., HoNZAK, M., LuCAS, R. (1998) Tropical forest biomass density estimation using JERS-1 SAR: Seasonal variation, 
confidence limits, and application to image mosaics. Remote Sens. Environ. 63:126-139

MuHAMAD N. Z. (2001) Management of tropical peatlands in Indonesia: Mega Reclamation Project in Central Kalimantan. http://www.geocities.com/kopitubruk/Report2.html?200924 (accessed on July 8, 2011)

OuchI, K. (2009) Principles of Synthetic Aperture Rader for Remote Sensing. Tokyo Denki University Publisher, Tokyo, 371pp (in Japanese)

Rosenqvist, A, Milne, A., Lucas, R., ImHoff, M., Dobsone, C. (2003) A review of remote sensing technology in support of the Kyoto Protocol. Environmental Science and Policy, 6:441-455

Rosenqvist, A., Shimada, M., Ito, N., Watanabe, M. (2007) AlOS PALSAR: A Pathfinder Mission for global-scale monitoring of the environment. IEEE Transactions on Geoscience and Remote Sensing, 45(11):3307-3316

Senoo,T., Nishi, T., Yoshikawa, T., Ohte, K., Tanaka, S., Sugimura, T.
(1995) Applicability of JERS-1 SAR data for monitoring of forest function and environment - Preliminary analysis of forest stand structure using JERS-1 SAR data for forest management - . Journal of Forest Planning 1:69-76

Shimada, M. (2010) Ortho-rectification and slope correction of SAR data using DEM and its accuracy evaluation. IEEE Journal of Selected Topics in Applied Earth Observations and Remote Sensing, 3(4): $657-671$

UNFCC (2007) Reducing emissions from deforestation in developing countries Draft conclusions. FCCC/SBSTA/2007/L.10, 4pp

YAMAGUCHI, Y. (ed.) (2001) Earth observations from the space Earth Remote Sensing Data Analysis Center, Tokyo, 275pp (in Japanese, The title is authors' tentative translation.)

(Received 14 March 2012)

(Accepted 5 November 2012) 